UDC: 811.111'255.4:004.738.2 https://doi.org/10.22190/JTESAP1803543D

\title{
WHY ENGLISH LANGUAGE TEACHERS' EMOTION LABOR?: AN INTERVIEW WITH PROFESSOR SARAH BENESCH
}

\author{
Xiaowei Ding ${ }^{1}$, Sarah Benesch ${ }^{2}$ \\ ${ }^{1}$ Beijing Information Science and Technology University, China \\ Phone: +8613621205090, E-Mail: dingxiaowei@bistu.edu.cn
}

\section{INTRODUCTION}

...the issue of emotion in language teaching and learning, which would seem to be an integral part of the aforementioned constructs in a person's identifications and performativities, was left largely unexplored from critical perspectives. Sarah Benesch's thought-provoking, and in many ways, groundbreaking book is a much needed and welcomed contribution to the exploration of emotions that extend beyond the cognitive approaches prevalent in Second Language Acquisition (SLA) research. (Chun 2014: 99)

As a scholar who has devoted herself to critical English language teaching and English language teacher emotion research, Professor Sarah Benesch is one of the pioneers exploring teachers' emotion labor from a critical perspective. Before her retirement, she worked as Professor of English at the College of Staten Island of the City University of New York. Her earlier research interest was critical English for Academic Purposes (Benesch 2001), but her current research focus is the relationship between teacher emotions and power in English language teaching. This more recent research is illustrated in her latest books: Considering Emotions in Critical English Language Teaching: Theories and Praxis (Routledge 2012) and Emotions and English Language Teaching: Exploring Teachers' Emotion Labor (Routledge 2017). The former was referred to as "a publication no one involved in education and specifically in teaching English as a second language should overlook (Gabrys-Barker 2013), and the latter was called "a major contribution to the growing literature on emotions in the field of applied linguistics" (Mott-Smith 2018).

For a better understanding of her conception of English language teachers' emotion labor, it is necessary and helpful to understand, first and foremost, the trajectory of her professional life as both a teacher and critical applied linguistics scholar, which is the purpose of this interview paper.

Submitted June $3^{\text {rd }}, 2018$, accepted for publication September $13^{\text {th }}, 2018$

${ }^{1}$ Corresponding author: Xiaowei Ding is an Associate Professor of English in the School of Foreign Studies at Beijing Information Science and Technology University. Her primary area of research is English education, teacher emotions, and in-service teacher development. 


\section{Why ENGLiSh LANGUAGE TEACHERS’ EMOTIONS?}

\subsection{Why Critical English Language Teaching?}

Xiaowei Ding (D): What was your earliest research interest? Why did you start out there?

Professor Benesch (B): In my early years as an academic I worked on English for Academic Purposes. The first book I edited, Ending Remediation: Linking ESL and Content in Higher Education (Benesch 1988), was about paired courses. My contribution to that collection was based on the collaboration between me, a reading professor, and a psychology professor in the Freshman Workshop Program, at the College of Staten Island. For many years, I taught ESL courses that were paired with psychology, economics, history and other content courses.

Though the Freshman Workshop Program posited an equal and collaborative role for language and content teachers, the scholarly literature did not. I was surprised the degree to which ESL was accepted as subordinate to content courses and ESL teachers as the handmaidens of content. According to the EAP literature at that time, we were supposed to make the material comprehensible to students. Content teachers, on the other hand, were not expected to accommodate the linguistic needs or level of their ESL students.

My interest in critical pedagogy led me to propose "critical English for academic purposes," to posit a more visible and active role for English language learners and teachers in responding to and shaping academic life. I further proposed critical needs analysis; my next iteration was rights analysis. Rights analysis is a conceptual tool for exploring openings with students for ways that they could intervene and change the pedagogy of the content class to make it more appropriate for them.

My 2001 book, Critical English for Academic Purposes, gave examples of that type of intervention. For example, I described an ESL class I taught that was paired with a cultural anthropology class. Toward the end of the semester, the anthropology professor began to add assignments that would have been hard to fulfill in the short amount of course time left. My students complained to me about these unanticipated demands and asked me to intercede. I suggested that it would be more effective for them to approach the anthropology professor themselves so they formed a delegation that went to speak to her. The upshot was that she revised the syllabus, making it more realistic given the remaining time. This is a small example of how you can change requirements and improve pedagogy if you encourage the students to imagine and work toward better conditions.

So that's where I started out, and I did that for a long time: Critical English for Academic Purposes. Then after a while, I needed a new topic.

\subsection{Why Power and equality?}

$\mathrm{X}$ : "Power" and "equality" are two recurring themes highlighted in your books. Why are you interested in them?

B: As I said earlier, when I started reading the literature on English for Academic Purposes, I was disappointed by the way the ESL teacher was positioned as less than or lower than the content teacher. And that began my journey of looking at power in English language teaching settings. My earliest publications questioned the way needs analysis was done in English for Academic Purposes where even the word "need" suggests something psychological rather than sociopolitical, as if academic requirements were congruent with 
what students needed. In traditional needs analysis, ESL specialists would attend their students' content classes, note the requirements, and then develop materials designed to address those requirements. By developing those materials, they were serving the content teachers, thereby subordinating themselves. The ESL teacher was seen as the person who would make that content approachable and understandable to the ESL students, with no modification on the part of the content teacher. Content teachers were at the top of the hierarchy.

I found that offensive because I believe all faculty members share responsibility for literacy teaching across the curriculum. That was my training as a graduate student: writing across the curriculum. Yet EAP positioned ESL teachers in that low position which I felt was a reflection of how ESL students themselves were seen in the academic hierarchy.

My interest in equality and social justice comes from my background. I grew up in Washington DC and attended a public high school where African American students were the majority. Attending DC public schools from elementary through secondary shaped my thinking and has informed my scholarship. As I wrote in the narrative at the beginning of my 2012 book, a section I call "My social/emotional history," I was in elementary school during the 1963 march on Washington led by Martin Luther King and I was in high school during the anti-Vietnam war demonstrations. We students were very involved politically.

I'm not a religious person, but culturally my ethnicity is Jewish. In Jewish culture, you're supposed to give back. You're supposed to be politically engaged. You don't just do things for yourself, your family, and your immediate community; you're supposed to help others. That was part of my background, too. So, where I grew up (Washington DC), when I grew up (the 1960s) and my family's cultural values have informed my academic interests.

\subsection{Why Teacher Emotions?}

D: What drove you to focus on teacher emotions in your more recent research work?

B: For years, I have been thinking about teaching as a very emotional experience; for me personally, extremely emotional. A lot of frustration, disappointment, joy, and confusion. Most of the time I was just angry, angry at the way the institution treated the students, the way they excluded them, the way they tested them. But I didn't know if there was a way to theorize emotions. I just knew that I wasn't interested in a psychological approach. When I realized there were scholars in various fields - feminist studies, sociology, geography, political science - who examined emotions from a political perspective, I began to read their work. Based on that reading, I proposed ways to theorize emotions in English language teaching in my 2012 book Considering Emotions in Critical English Language Teaching: Theories and Praxis.

You can't write about emotions without theorizing them, although some do. You have to lay out your assumptions. You have to grapple with certain questions like: What is an emotion? Is it a thing? Is it a physical feeling? Is it a construct? Is it inside? Is it outside? Is it in your head? Is it in your body? Is it inherited? Is it socially constructed? These are questions I attempted to deal with in the 2012 book.

It's exciting to have settled on the topic of teachers' emotions, especially at this stage of my career. Though I retired from teaching, I still write about this topic because it continues to fascinate me. 


\section{WHY ESL TEACHERS' EMOTION LABOR?}

D: You discussed ESL teachers' emotion labor in only one chapter of your 2012 book. But in your 2017 book, you developed a poststructural/discursive theory of teachers' emotion labor. Why did you decide to further study teacher emotion labor?

B: The 2012 book was my first attempt to theorize emotions critically and to apply that theory to classroom situations. So that book was more general and it included chapters on students' emotions. The 2017 book is more streamlined. I wanted to explore the concept of teachers' emotion labor more fully because I think it demonstrates so clearly the relationship between emotions and power. It looks at how teachers' emotions are regulated in academic institutions, and how teachers respond to the so-called feeling rules: Do they resist or comply? So, it's about power.

\subsection{A Poststructural Perspective}

D: It seems that you have constructed the concepts of "Emotion" and "Emotion Labor" from a poststructural, discursive, and critical perspective. Would you please clarify the term "poststructuralism" in your works?

B: Poststructuralism is a reaction to structuralism, which studies social phenomena, culture, for example, by breaking them down into small components that are quantifiable. The structural claim is that these components comprise the reality of the phenomena they seek to describe.

Poststructuralists say that these categories are inventions that simply create rather than reflect a reality. Once you identify these categories and sub-categories and quantify them and test them, they become naturalized. But they're not natural. The naming of categories and subcategories is a discursive process that has to be acknowledged as such, according to poststructuralism.

Poststructuralism is a refusal to accept the categories. It questions the labels. When it comes to emotions, it asks, for example, "What does happy mean?" It rejects the assumption that happiness is a universal basic emotion. Instead, it sees happiness as a social construct. Sara Ahmed's work on the social construction of happiness, The Promise of Happiness, is very instructive in this regard.

On the other hand, a contrast would be the structuralist work of psychologist Paul Ekman. He went out in the field and showed people pictures of human faces that he had predetermined showed particular emotions. He tried to demonstrate that regardless of culture and geography, humans share certain basic emotions that are identifiable and universal. And he claimed that his field research demonstrated the reality of basic universal emotions. That's a structural approach

It's the same with structural linguistics. Language is divided up into phonetics, phonology, syntax, etc., all of which are further subdivided and tested in an attempt to describe language. Or Chomsky's theory of Universal Grammar. The claim is that grammar is inherited and the aim is to identify and test universal variables to prove the theory. Poststructuralism says that just because you claim that these linguistic variables are universal, biological, genetic, doesn't mean it's true. You're coming up with these categories, and then you're attempting to prove their reality, their existence. Poststructuralism says, "Let's just get rid of all those categories, and look at the social process of naming." Who does the naming? Who gets named? What are the consequences 
of those labels? So poststructural/discursive approaches reveal the social processes of labeling, of categorizing, of naming and their relationship to power.

\subsection{The Discursive Perspective}

D: What is your understanding of the discursive perspective?

B: The discursive perspective is about the social process of naming. For example, in English, if I have fluttering in my belly, I might call that anxiety, because that's how we label that sensation. English speakers learned to apply that name to that sensation when they were learning L1. Whereas if I have a headache, or an earache, we don't have an emotional label for that. So, the process of naming emotions is discursive. It's learned. It's social.

Another example of a discursive approach is something I did in a sociolinguistics class. I put up on the board "Miss", "Mrs." and "Ms.". I then asked the students to tell me their meaning. They said that "Miss" is an unmarried woman, "Mrs." is a married woman, and "Ms." is somebody who has never got married, or is divorced. I was surprised by that because the word Ms. was invented in the 1970s for the purpose of having a female equivalent of "Mr.", a label that doesn't refer to one's marital status. The fact that "Ms." has still not caught on for that purpose tells you that men and women are still not equal. Women are still identified according to their marital status. It's an example of the relationship between language and power.

\subsection{The Critical Perspective}

D: What do you mean by taking a critical perspective in your research on emotions?

B: Taking a critical perspective means attention to power. Questions about emotions and power include: Which emotions are accepted in different social situations? Who is allowed to exhibit certain emotions? Which are deemed unacceptable? Who decides? How is this process gendered? Raced? And so on. What are the feeling rules? These types of questions relate emotions and power.

\subsection{The Term "Labor"}

D: The term "labor" is borrowed from Marxist theory of political-economics. According to Hochschild, emotional labor is the third labor in addition to physical and intellectual labors because the employees' management of emotions in public is commercialized and connected to the payment they receive as salary or wage. However, teachers are kind of different from employees in the service sector because when we manage our emotions in teaching, keeping the job is less important. We adjust our emotions according to factors other than financial ones, such as our belief in education and our career, and our conscientiousness. So, do you think the term "labor" is suitable to conceptualize teachers' emotion struggles?

B: The reason I used "labor" is because I wanted to bring power into the study of emotions, as I said before. "Labor" has a certain connotation in English of the power differential between management and workers. In my context, a publicly-funded university, we are laborers; we are workers and we are regulated by upper management: deans, presidents, chancellors, trustees, and politicians, who provide the funding. So, there is a hierarchy. Even though we might want to believe that we are autonomous in our 
classrooms, I wanted to emphasize the hierarchy of power and decisions that are made at the top and enforced in a top-down way. So that's why I insist on the use of "labor." I want to demystify the notion of teaching as this white color job where we contribute out of the goodness of our hearts without money or power coming into play.

In the City University of New York, we are actually civil servants; we are paid according to a civil service scale, and we are also members of our labor union. We really are laborers in that sense. So I agree with you that teachers have their beliefs, their training, their education, a conscientiousness as you said. But we never want to lose sight of power.

If you're going to talk about emotions in teaching, a way to maintain the focus on power is to talk about emotion labor. So bringing in "labor" was a deliberate choice.

Emotion labor is inevitable because in every institution there is a power imbalance between upper management and lower management. It's there; you can't extinguish it. We need to acknowledge it in teaching, and then use it as a vehicle for agency and transformation. The relationship between English language teachers' emotions and power is an important contribution to the study of emotions in ELT, in other words, teachers' emotion labor.

\subsection{The Term "Performativity"}

D: You mentioned in your 2017 book that you focus more on what teacher emotions do socially, as you cited Ahmed (2004, 2010), rather than what emotions are. Emotions' function of "doing things" is also referred as its "performativity", a term derived from Austin's "performative speech" in the Speech Act Theory, and expanded and applied in social studies by scholars such as Judith Butler in her Gender Performativity Theory. However, the term performativity is kind of ambiguous because some scholars also refer it to Erving Goffman's classic theory of Dramaturgy and Performance. Do you prefer to another term for the performance of emotion labor, considering this ambiguity?

B: What I was trying to do with bringing in Ahmed was to find a way to theorize emotions, not as something inside of us, but something that is social. Ahmed (2004, 2010) talks about emotions as being effects of encounters between humans and objects, ideas, animals, locations, and so on. These objects of emotions circulate socially, and become sticky with affect. Take the word "terrorist", for example. It is very emotionally laden due to its contact with media images, racism, Islamophobia and so on. So this was a way to theorize emotions from a cultural perspective.

I don't really think of emotion labor as a performance or an activity in that way. I conceptualize it as the inevitable result of a clash between feeling rules and workers' personal beliefs, training, expectations, and so on. That's the classic definition of emotion labor that Hochschild proposed. However, she posited an authentic self that is violated by unreasonable feeling rules. I don't. I say that emotion labor happens because of this clash, but it doesn't require that I have this notion of an authentic self that can be psychologically harmed by feeling rules, such as having to smile constantly as flight attendants in her research were trained to do.

The clash can simply be, for example, that I start working in an educational institution and I'm expecting to be able to teach in ways that comport with my training, my beliefs, and my expectations. But then I'm faced with, for example, high-stakes testing, an ambiguous attendance policy, or a plagiarism policy that constructs students as criminals. This flies in the face of my expectation, and that creates emotion labor, because it's not 
what I am trained to do or hope to do. It's not that my authentic self is violated. It's that this clash leads to confusion about how to behave. So taking that a step further, I don't say that we should get rid of emotion labor. I say there's no way to get rid of it. As long as there's a power differential, you will have emotion labor that we need to acknowledge and even build upon as a way for political action, for change, and for transformation. So I don't say that people perform emotion labor.

\section{LIMITATIONS AND FUTURE DIRECTIONS}

\subsection{Methodology of Teacher Emotion Labor Research}

D: Do you see limitations, if any, in your recent books? What would you like to recommend regarding future studies of teachers' emotion labor?

$\mathrm{B}$ : As far as limitations are concerned, it is finding ways to test the theory by tweaking the methodology. I think there is room for improvement there. The theory needs to be tested. How do you test it? How do you apply the theory, collect the data, analyze the data, and report the findings? That's the tricky part. I did a preliminary study of emotion labor based on semi-structured interviews, and discursive analysis of the data. But there's always room for improvement, like to triangulate the data, to get back to the students and teachers, and ask them if this is what they meant. If I were to do another study of teachers' emotion labor, I would tweak the methodology.

In terms of future studies of teachers' emotion labor, we have the example of Zembylas's (2005) year-long case study of one kindergarten/first grade teacher. His participant kept an emotion diary, and he observed her classes. The findings were very interesting: she reported to him that she had a lot of enthusiasm for teaching. But her colleagues and the school emphasized the mandated curriculum and getting students to pass standardized tests, and so on. They found her enthusiasm off-putting and irrelevant. Yet, even though she couldn't share her enthusiasm with colleagues, it sustained her and created bonds with her students. She defied the institution's feeling rules. That type of case study of an English language teachers' emotions or an auto-ethnography would be an interesting contribution.

\subsection{Embodiment of Teacher Emotion Labor}

D: Why do you mention the embodiment, the physical aspect, of emotion labor only in that chapter relating to absence? For example, when you told the story of plagiarism, actually teachers reported that they didn't want to hurt their students' feelings. So they tried to talk about this writing problem in private, not in public. And then they tried to change this into the situation in which the students might not completely understand the writing rules, not just labeling the student as cheaters or criminals.

B: Right. So you feel like that's embodiment because of the privacy part: taking the student away from the group and dealing with it one-on-one? That's interesting. I mean I think that's a really interesting observation and something to be considered.

The reason I focused on embodiment with absence and lateness is because it's so obviously about bodies, whether or not they're present. So it's an example, methodologically, about how you might bring embodiment to a study of emotions. Could I have done it more in the other chapters? Absolutely. And I would encourage that. I like 
your example of privacy as an aspect of embodiment. Now that you mention it, there is a lot of embodiment in responding to writing, too, where my respondents said, "I do it in a doctor's office or on the subway. I don't do it in my office because my office is so crowded." Or contingent faculty who don't have offices. There is definitely a physicality to it. I appreciate your bringing it up because it's something that could probably be addressed more fully.

\subsection{Diverse Topics in Teacher Emotion Labor Research}

D: What else would you like to share before we conclude this interview?

B: One of the things that I did do at the end of the interviews was to ask for other topics that the respondents would have liked me to address related to emotions and English language teaching. I called that section of my 2012 book "anything else?". A few said, "You didn't do anything about speaking." So that's a topic that could be addressed: how students speaking in class or not is related to language teacher emotions.

One of the other areas which I think is extremely important and I didn't cover is teacher evaluations. This is clearly a topic that relates power and emotions in a hierarchical manner. For example, there are some schools and universities that evaluate teachers according to scores their students receive on standardized tests. That's outrageous. When it comes to universities, students generally enter when they're eighteen. What about all the years prior? The teachers are being evaluated without those years being considered. I'm assuming that generates emotion labor for the teachers, who feel extremely put upon to be responsible for something that they had no part in making.

I chose just four topics for my interviews for the 2017 book: high-stakes literacy testing, responding to writing, plagiarism, and attendance. There are many others. I would love to see more studies of this type, where teachers are asked, in ways that I haven't anticipated myself, about other topics that relate emotions and power. It would be wonderful to see that.

Acknowledgement: This paper is sponsored by the "Higher Education Research Project (No. 2015GJYB03)" of Beijing Information Science and Technology University and the "Support Project of High-level Teachers in Beijing Municipal Universities in the Period of 13th Five-year Plan (No. 067175315000)”.

\section{REFERENCES}

Ahmed, Sara. The Cultural Politics of Emotion. New York, NY: Routledge, 2004.

Ahmed, Sara. The Promise of Happiness. Durham, NC: Duke University Press, 2010.

Benesch, Sarah, Ed. Ending Remediation: Linking ESL and Content in Higher Education. Alexandria, VA: TESOL, 1988.

Benesch, Sarah. Critical English for Academic Purposes: Theory, Politics, and Practice. Mahwah, NJ: Lawrence Erlbaum Associates, 2001.

Benesch, Sarah. Considering Emotions in Critical English Language Teaching: Theories and Praxis. New York, NY: Routledge, 2012.

Benesch, Sarah. Emotions and English Language Teaching: Exploring Teachers' Emotion Labor. New York and London: Routledge, 2017.

Chun, Christian W. "Sarah Benesch: Considering Emotions in Critical English Language Teaching: Theories and Praxis." Applied Linguistics 35(1) (2014): 99-102.

Gabrys-Barker, Danuta. "Considering Emotions in Critical English Language Teaching: Theories and Praxis.” TESOL Quarterly 47 (2013): 208-210. 
Mott-Smith, Jennifer A. "Sarah Benesch: Emotions and English Language Teaching: Exploring Teachers' Emotion Labor." Applied Linguistics, March 23, 2018. <https://doi.org/10.1093/applin/amy013> (22 April 2018).

Zembylas, Michalinos. Teaching with Emotion: A Postmodern Enactment. Greenwich, CT: Information Age Publishing, 2005. 